\title{
MISCELLANEA
GEOGRAPHICA
}

W A R S Z A W A 1988

Alicja Krzymowska-Kostrowicka

\section{THEORETICAL AND METHGDOLOGICAL FOUNDATIONS FOR STUDIES OF INTERRELATIONS BETWEEN RECREATION AND NATURAL ENIIRONMENT IN SUBURBAN ZONES}

One of the fundamental factors shaping natural environment in suburban zones is broadly conceived recreation. The mass toursim and recreation movement encompassing a wide range of various forms of leisure, having different intensity and duration time, cause on the one hand downgrading of the state of nature, but, on the other hand, protect nature's values. This duality of influence exerted on nature by recreation causes that this form of human activity conduccted within nature should be a subject of especially thorough studies, particularly for the areas of high concentration of tourism-and-recreation movement. such as. for instance, suburban zones. It is in the zones that does appear the phenonenon of accumulation of many functions, both economic and social, which collide in a variety. of ways, these collisions influencing the efficiency of functioning of the whole suburban spatial setting. Thus the possibilities of recreation for the inhabitants are limited and, ultimately, recreation functions are concentrated within definite, relatively small areas. The result is local overcongestion of recreating people, leading to environmental disruption and lowering the effectiveness of thus realized recreation. In this situation it becomes essential to recognize precisely, on the basis of maximally objective scientific foundations, the resources and the value of environment, and therefore its resilience, carrying capacity, attractiveness and other important features.

Natural environment gains increasing importance in terms of the types of recreational resources. It is only natural environment that can provide adequate conditions for the appropriate restitution of physical and psychological forces of a human being. Simultaneously, population growth, spatial spread of urban areas, as well as agriculture and forest economy conducted in a non-rational manner cause continuous decrease of the areas fit for recreational use.

The fundamental spatial-typological unit of geographical environment is landscape, that is, a set of elementary settings of lower order mutually interrelated functionally and therefore mutually dependent, (see A. Richling 
1976). Structure of these settings and of the landscape as a whole is formed by three groups of elements: exogeneous (air and water), endogenous (underlying rocks, soils. plants and animal world), as well as anthropogenic ones (various sorts of man-made artifacts). Owing to relations which exist among these elements, landscape acquires features of a system-of a certain coherent whole. Therefore, a person using landscape through recreation is using this landscape in this totality even when the person is directly addressing just one of its component elements. e.g. water or forest.

System's features of landscape imply far-reaching methodological consequences. First of all, it turns out that it is not feasible to draw definite conclusions as to the features of environment, especially as to it: adequacy for recreation, solely on the basis of knowledge of just one component element of landscape. Thus, it is necessary to conduct comprehensive studies, approaching in a holistic way the variables of this system. since it is only in this way that the so-called "integrons", that is, these characteristics which link particular elements so as to form coherent wholes, can be identified. "Integrons" can be seen only on a higher, supraelementary organization level. They can be identified via an indirect manner, by concentrating on studies of these elements, or variables, which display overinformative characteristics, e.g. vegetation cover or water systems.

From the point of view of possibility of toursim-and-recreation type of utilization of natural environment it becomes especially significant to identify the following four parameters of this environment: resilience with regard to recreational use, flexibility, biotherapeutic features, as well as functional and visual attractiveness. First two parameters can be measured, the third one can be estimated, and the last one can be evaluated. These four parameters together express the "utility" of natural environment as recreational resource

Influences of the tourism and recreation activities and of the regional and spatial management related to these activities may have the following nature:

- degradative impact, lowering functional effectiveness of the geo-ecological system, with maintenance of its structural features,

- degenerative impact, which destroys both the structure and the functioning of a geo-ecological system,

- suppletive impact which enriches the given geo-ecological system with new values.

From the point of view of the recreating persons, i.e. users of natural environment, two further negative effects should be added to the ones mentioned already above: disfunction of the nature's system, which strips this system off its leisure-wise values, and decomposition of environment, that is its aesthetical pollution. 
The basic task in the studies of interrelations between the natural environment and recreation is to perform of identification of natural resources from the point of view of their utility for recreation

In the identification studies two approaches are applied: analytic approach, i.e. identification of variables corresponding to particular components separately, e.g. climatic conditions, water relations, plant cover etc., and synthetic approach, i.e. identification of utility of an environmental system as a whole.

A good point of the first approach is the possibility of acquiring precise quantitative data describing the state of particular components, while its shortcoming consists of complete omission of synergic actions resulting from cooperation of these components which in fact determine the level of the so-called physiological recreational efficiency of environment.

The second, synthetic approach is more difficult to express in quantitative terms, especially through concrete measurements. In view of thousands of links among particular elements of environment, through which this environment forms a structural-functional whole - the geosystem, direct application of physical and physico-chemical measurement techniques is simply impossible. It is, therefore, necessary to either concentrate on these elements of natural environment which display overinformative features (plant cover belongs here, first of all, since it explains some $75 \%$ of the total variability of the variables representing the geosystem and then water relations, which explain some $60-65 \%$ of this variability), or to reverse the procedure taken, that is, to measure rather human variables than variables describing nature. In other words, this reversal would mean measurement of reactions rather than causes. Difference outlined can be represented through the following equations:

(a) Analytical approach

$$
n_{x_{1}} \rightarrow p \rightarrow c ; n_{x_{2}} \rightarrow p \rightarrow c ; n_{x_{3}} \rightarrow p \rightarrow c ; \text { etc. }
$$

(b) Synthetic approach

$$
\left(n_{x_{1}}+n_{x_{2}}+n_{x_{3}}+\ldots+n_{x_{n}}\right) \rightarrow p \rightarrow c
$$

(c) Anthropocentric approach

$$
\left(n_{x_{1 . . n}}\right) \rightarrow\left(p c_{y 1}, \ldots, p c_{y_{n}}\right)
$$

where: $n_{x}$ - variables of natural environment, $p-$ measurement, $c$ - human subsystem, $c_{y}$ - physiological-psychophysical variables of man.

It should be stated here that, irrespective of the formula adopted, identification should always have objective and verifiable nature. This is where the difference between identification and evaluation lies, evaluation not requiring rigorous observation of verifiability and verification. 
Identification studies are conducted from two, in a way opposing, directions: determination of recreational utility of natural environment and its fit for definite forms of use, and determination of influences exerted by these forms on the environment. In identification of recreational utility of natural environment and of its usefullness various methods and techniques of measurement are applied, depending upon the purpose and degree of precision of studies undertaken.

When the goal is to determine the utility of a given environ-. ment type (geosystem, ecosystem etc.), the appropriate value is obtained as the deviation from the maximum possible utility, for instance according to the following formula (see Kostrowicka, 1978):

$$
W_{g^{i}}=S\left(\frac{W_{k_{i}}}{W_{k_{o}}} ; \frac{W_{w_{i}}}{W_{w_{o}}} ; \frac{W_{l_{i}}}{W_{w_{o}}} ; \frac{W_{r_{i}}}{W_{r_{o}}} ; \ldots\right)
$$

where: $W_{g_{i}}$ - overall utility of a geosystem; $S$ - index of synergism of the system, measured by the number of integrons; standardized utility of particular types of conditions within a given geosystem: climatic conditions - $\left(W_{k_{i}}\right)$, lithological and soil conditions - $\left(W_{l_{i}}\right)$, plant cover conditions - $\left(W_{r_{i}}\right)$, water system conditions - $\left(W_{w_{i}}\right)$, and other types, for the $i$-th geosystem; $W_{k_{o}}, W_{w_{o}}, W_{l_{o}}, W_{r_{o}}$ - theoretical maximum possible utility value of particular components, adequately standardized.

If instead of the theoretically maximal possible value one adopts, e.g. average value for a given area or region, then, of course, the result obtained shall indicate the deviation from this average within $i$-th geosystem.

When other criteria are adopted, such as e.g. recognition of relations between positive and negative features of the system considered, the approach of I. Burton (1975) can be applied, based upon the following formula:

$$
d Q E=\left(\sum_{i=1}^{n} a_{i} d X_{i}\right)-\left(\sum_{i=1}^{n} a_{s} d B_{s}\right) \rightarrow \max
$$

where: $d Q E$ - overall utility of environment; $d X_{i}$ - sum of positive features of environment; $d B_{s}$ - sum of negative features of environment; $a_{i}, a_{s}$ - relative weights depending upon the expected or current forms of leisure; input is usually presented in the form of matrix $(I \times S)$.

This simple formula can be quite easily broadened so as to encompass, for instance, human influence on natural environment and on selfregulatory capacities of geosystems etc.

A separate problem is related to natural consequences of recreational use of environment. These consequences depend upon the resilience and flexibility of a given environment, and their threshold value, which can be taken as a yardstick, is defined limit carrying capacity, i.e. maximum admissible 
natural absorptiveness of a geosystem. In studies conducted in Poland this magnitude is usually determined via applicatiom of the formula of A. Marsz (1972) or of A. S. Kostrowicki (1979). The method proposed by A. Marsz gives less precise results, but is easier in application, while the one suggested by A.S. Kostrowicki, although yielding more precise output, requires, first of all, a good knowledge of the plant cover.

The formula of A. Marsz has the following form:

$$
\begin{aligned}
N & =\frac{w}{1+\left(1-S_{z}\right)}(1-3 \mathrm{tg}) \text { for light soils } \\
N & =\frac{w}{1+S_{p}}(1-3 \mathrm{tg}) \text { for compact soils } \\
N & =\frac{w}{1+\left(1-S_{p}\right)}(1-4 \mathrm{tg}) \begin{array}{l}
\text { for areas with more than } 6 \\
\text { degress of slope }
\end{array}
\end{aligned}
$$

where: $N-$ is the carrying capacity indicator; $w-$ degree of endurance of plant cover to treading; $S_{z}-$ soil density index; $S_{p}$ - soil plasticity index; $(1-3 \mathrm{tg})$ and $(1-4 \mathrm{tg})$ - slope angle of the area.

The formula of A.S. Kostrowicki has the form of

$$
0=5 \cdot \frac{\bar{W} \cdot S}{N}
$$

in which: 0 - magnitude of limit of charge on undergrowth; $\bar{W}$ - averaged sensitivity of plant cover to mechanical destruction (treading); $S-$ index of soil compactness; $N$ - index of slope angle; $5-$ this coefficient results from proportionality taken, i.e. 0.2 hectare per person with continuous 8-hour penetration.

An inevitable stage in the studies of interrelations between recreation and natural environment is the evaluation, that is, mapping of the set of characteristics of the object evaluated into the set of value magnitudes, resulting from evaluation. Thus, evaluations formulated are not equivalent to expression of relations, among the variables measured, but rather their interpretations, transforming them into a value system. All evaluation is therefore of relative nature, depending on currently preferred, or obligatory, value systems.

In the studies of interrelations between recreation and natural environment two types of evaluation techniques are being applied-quantitative and qualitative one.

The first one is a transposition of quantitative measurements into the set of evaluations performed with such various formal approaches as ranking, standardizing, norming etc. Its main positive feature consists not so much of its precision as of the possibility of backward transportation, that is of 
transforming the set of evaluations again into the set of measurement results.

When multi atribute systems are being evaluated, it becomes necessary to standardize the magnitudes of particular attributes, by ascribing them appropriate weights, calculated as the product of rank and significance (rank is being defined, for instance, by the magnitude of surface used for recreation purposes, and significance is determined by the method of experts or by polling the vacationists, tourists and holidaymakers). The set of weights can be presented in the form of summary index of the natural enviroment's recreational value.

Most often, however, qualitative techniques are used in real practice. These techniques are, in a way, a transformation of social intuitions into the sets of evaluations (intuition is in this case understood as the currently prevailing, but therefore generally changing over time, view on the quality, value and utility of a given good). Intuitive judgements are usually formulated by experts in the course of the procedure.

One of the fundamental tasks of evaluation of recreation resources of the environment is the assessment of their attractiveness. Attractiveness is a relative notion, belonging to the domain of applied axiology. Generally speaking recreation attractiveness is the set of characteristics or attributes of environment which are, according to a social view, attributed definite quality or attraction force. Thus, the notion of attractiveness cannot be equated with another one, of functional usefulness. An area with high functional usefulness must not necessarily be perceived as attractive. The best situation would, of course, occur, when usefulnesss and atractiveness fully coincide spatially, since appropriate points could then get twice higher evaluation.

There exist various methods of assessing, ranging from descriptive to thoroughly formalized. Generally speaking, attractiveness of a given area can be represented in the following functional form (see A. Kostrowicka, 1978):

$$
A=f_{r}\left(k_{z}, k_{p}, k_{e}, k_{o}\right), \quad \text { for } r=1,2, \ldots, R
$$

in which: $A-$ is the overall attractiveness indicator; $k_{z}-$ is health attractiveness; $k_{p}$ - is psychological attractiveness, being a function of the choice capacity; $k_{e}$ - is aesthetical attractiveness, measured by the landscape variability index; $k_{o}-$ is attactiveness of living standard, measured by the quality and variety of service offered; $r=1, \ldots, R$ are indices of particular forms of recreation, treated separately.

While the assessment of health attractiveness, psychological comfort and living standards or at least may seem relatively simple, this is certainly not the case with the assessment of the aesthetic attractiveness of natural environment (landscape), which poses many difficulties, resulting not only 
from differences in tastes and likes of the public, but also from the specific ways of perceiving reality and, therefore, from the ways of evaluating it, as well.

One of the methods of evaluating aesthetic attractiveness of landscape can be represented in the form of the following formula:

$$
A=\log (\alpha N-\beta D)
$$

where: $A-$ is summary attractiveness of landscape; $N-$ is the over-all number of harmonious macro-diffrentiations of elements in space outlines and patterns, plant formations, aichitectural and historical monuments etc.; $D$ - is the total number of perceived disharmonious macro-differentiations of elements in space; $\alpha-$ is the positive variance index calculated from the formula:

$$
1-\left[\sum_{j=1}^{k} \frac{n_{j}\left(n_{j}-1\right)}{N(N-1)}\right]
$$

in which: $n_{j}$ - are numbers of visible replications of the harmonious image indexed $j$, and $k$-is the total number of images in space;

$\beta$ is the negative variance index calculated from the formula:

$$
1-\left[\sum_{i=1}^{m} \frac{d_{i}\left(\mathrm{~d}_{i}-1\right)}{D(\mathrm{D}-1)}\right]
$$

in which: $d_{i}$ - are number of perceived disharmonious replications, and $m$ - is total number of disharmonious images in space.

K. Wojciechowski (1986) proposed another approach to aesthetic assesment of landscape, the approach being based upon the relation

$$
A=\mathrm{f}(C, H, R, K, U)
$$

where: $C-$ is the measure of perfectness attained by the comfort and security attribute, $H-$ is the measure of the entire landscape harmony, $R$ - is the measure of landscape diversification, $K-$ is the measure of landcape composition and $U$ is the measure of landscape uniqueness.

The results of identification and evaluation of natural environment with regard to recreational use do not constitute the ultimately decisive criterion in allocation of space. Determination of function to be performed by particular areas may only be done when all the other factors, not related to nature, are also taken into account, including social demand for recreation services, transport-wise accessibility of the area, technical and material infrastructure, recreation programme envisaged, etc.

It is obvious that in the direct neighbourhood of urban centres vacationers and, more generally, recreation-consumers, shall concentrate even there. where natural conditions in at least minimum degree corresponded 
to the needs of leisure. Thus, the effective recreational value of an area is defined by the relation

$$
W_{i}=f\left(\frac{N_{i}, Z_{i}, P_{i}}{\frac{1}{D}}\right)
$$

in which: $W_{i}$ - is the summary recreational value of the area indexed $i ; N_{i}$ - is the sum of natural and historico-cultural values of an area; $Z_{i}-$ is the sum of values of technical and material infrastructure and service system within the given area; $P_{i}$ - is the sum of values of recereation programme deployed in the area, and $D-$ is transport and comunication-wise, as well as financial accessibility of this area.

The model of research approaches to study of relations between recreation and natural environment presented here, is currenly being applied in the detailed studies conducted within the suburban zone of Warsaw.

\section{REFERENCES}

Burton, I., 1975, Programme on Man and the Biosphere MAB, Perception of Environmental Quality. Final Report. UNESCO, Paris.

K ostrowick a, A., 1978, „Informacja o sostojanii issledowanija wzaimodejstvii miezhdu riekreacjonnoj diejatielnostiu $i$ prirodnoj sredoj $w$ sistiemonom izlozhenii” (Information on the state of research on relations between recreation activities and natural environment in system approach), Innformacionnyi Biuleten o nauczno-issledowatelskoj tiemie SEW 1.3., vol. 11 IG CSAV, Praha.

Kostrowi cki, A. S., 1981, „Metoda określania odporności roślin na uszkodzenia mechaniczne powstałe na skutek wydeptywania" (A method for determing plant endurance with regard to mechanical damage resulting from treading), Prace geograficzne IG i PZPAN, No. 139.

M a r s z, A. A., 1972, „Metoda obliczania pojemności rekreacyjnej ośrodków wypoczynkowych na niżu" (Calculation method of recreation capacity of health resorts in a lowland), Prace Kom. Geogr.-Geolog. PTPN, Poznań, 12, No. 3.

R ichling, A., 1976, "Frequency and force of interdependences between components of the geographical environment", Geographia Polonica, 33.

Woj c i c ch owski, H., 1986, Problemy percepcji i oceny estetycznej krajobrazu (Problems of perception and aesthetical evaluation of landscape), Ph.D. thesis, UMCS Lublin. 